\title{
CIÊNCIAS, TRABALHO E EDUCAÇÃO NO SISTEMA PENITENCIÁRIO BRASILEIRO
}

\author{
Roberto da Silva ${ }^{1}$ \\ Fábio Aparecido Moreira ${ }^{1}$ \\ Carolina Bessa Ferreira de Oliveira ${ }^{I}$
}

RESUMO: Este artigo tematiza as relaçóes entre as diversas áreas de conhecimento e respectivos profissionais que atuam na execução penal no sistema penitenciário brasileiro. O tema é relevante porque partimos do pressuposto de que a ressignificação dessas áreas de conhecimento pode alterar a forma como se faz educação e gestão do trabalho dentro da prisão. A tese a ser explorada no artigo problematiza a subordinação epistemológica das ciências humanas, sociais e biológicas às ciências jurídicas como causa da fragmentação epistemológica do conhecimento, à qual corresponde a fragmentação das especialidades profissionais, bem como a fragmentação das políticas, programas, projetos e açóes destinadas ao tratamento dado às pessoas privadas da liberdade. A conclusão do artigo aponta para a necessidade de um projeto político pedagógico que articule e integre os saberes existentes na prisão e o trabalho dos diferentes profissionais, sobretudo em virtude da mudança do perfil da população atendida e do entendimento de que todos os saberes são úteis e necessários à educação da pessoa privada da liberdade.

Palavras-chave: Sistema penitenciário. Trabalho. Educação. Relação entre ciências. Subordinação epistemológica.

${ }^{1}$ Universidade de São Paulo, Faculdade de Educação - São Paulo (SP), Brasil. E-mail: kalil@usp.br, fabiogeduc@hotmail.com, carolbessa@usp.br

DOI: 10.1590/CC0101-32622016162557 


\section{Sciences, work and education in the Brazilian prison system}

ABSTRACT: This article thematizes the relationships between the various areas of knowledge and their professional working in criminal enforcement in the Brazilian prison system. The issue is relevant because it is assumed that the redefinition of these areas of knowledge can change the way we do education and work management within the prison. The thesis to be explored in the article questions the epistemological subordination of human, social and biological sciences to legal science as a cause of epistemological fragmentation of knowledge, which corresponds to fragmentation of professional specialties as well as the fragmentation of policies, programs, projects and actions for the treatment of persons deprived of liberty. The conclusion of the article points to the need for a political pedagogical project that will link and integrate the existing knowledge in prison and the work of different professionals, mainly because of the profile of the change of the population served and the understanding that all knowledge is useful and necessary for the education of persons deprived of liberty.

Keywords: Penitentiary system. Work. Education. Relationship between sciences. Epistemological subordination.

\section{INTRODUÇÃO}

Erwing Goffman consolidou o entendimento de que a prisão é uma instituição total, ou seja, "estufas onde se faz experiências com o eu" (1986, p. 18).

Dentro dessa instituição total existem áreas de conhecimentos e atuam profissionais que se ocupam do mesmo objeto de estudo, referenciados em uma mesma norma jurídica para a consecução dos objetivos de uma mesma política criminal e penitenciária.

A presença e atuação dos profissionais do Direito, da Psiquiatria, Psicologia, Serviço Social, Ciências Sociais e Pedagogia no sistema peni- 
tenciário deve-se à determinação da Lei de Execução Penal (LEP), Lei Federal no 7.210/1984, que assim dispóe:

Art. $7^{\circ}$ - A Comissão Técnica de Classificação, existente em cada estabelecimento, será presidida pelo diretor e composta, no mínimo, por 2 (dois) chefes de serviço, 1 (um) psiquiatra, 1 (um) psicólogo e 1 (um) assistente social, quando se tratar de condenado à pena privativa da liberdade.<smiles></smiles>

Art. 75 - O ocupante do cargo de diretor de estabelecimento deverá satisfazer os seguintes requisitos:

I - ser portador de diploma de nível superior de Direito, ou Psicologia, ou Ciências Sociais, ou Pedagogia, ou Serviços Sociais. (BRASIL, 1984)

Psiquiatras, psicólogos e assistentes sociais - nos termos da Comissão Técnica de Classificação (Art. $6^{\circ}$ ao $9^{\circ}$ da LEP) — cumprem a função de "orientar a individualização do cumprimento da pena, separando os condenados mais perigosos dos eventuais e estabelecendo as diretrizes para o tratamento mais adequado de cada um" (BRASIL, 1984, p. 1).

A presença de profissionais oriundos de outras áreas também se dá em decorrência das obrigaçóes legais que o Estado reserva para si em relação ao sentenciado.

Art. 10 - A assistência ao preso e ao internado é dever do Estado, objetivando prevenir o crime e orientar o retorno à convivência em sociedade.

Art. 11 - A assistência será:

I - material;

Il - à saúde; 


$$
\begin{aligned}
& \text { III - jurídica; } \\
& \text { IV - educacional; } \\
& \text { V - social; } \\
& \text { VI - religiosa. (BRASIL, 1984, p. 1) }
\end{aligned}
$$

Todos os profissionais designados para prestar as assistências e os serviços estipulados pela Lei de Execução Penal, com exceção da assistência religiosa, são funcionários do Estado, inclusive os professores e instrutores de ofícios na Educação Técnica e Profissional.

Essa conjunção de conhecimentos e de profissionais de diversas áreas de atuação em um mesmo campo de trabalho possibilita configurar o que Thomas Kuhn, no livro A Estrutura das Revoluçóes Cientificas, denomina comunidade cientifica:

Uma comunidade científica é formada pelos praticantes de uma especialidade científica. Estes foram submetidos a uma iniciaçáo profissional e a uma educação similares, numa extensão sem paralelo na maioria das outras disciplinas. Neste processo, absorveram a mesma literatura técnica e retiraram dela muitas das mesmas liçôes. (KUHN, 1998, p. 220).

Ainda que desgastado pelo uso abusivo do prefixo "re", a socialização, inserção e educação do condenado é o objetivo de todas as ciências presentes no ambiente prisional e o eixo articulador do trabalho de seus profissionais, como afirma um diretor da Penitenciária Industrial de Guarapuava.

O que se faz é ressocialização, reeducação, reinserção social e privaçáa de liberdade. Indica que dentro da prisão as mudanças do preso são feitas a partir do trabalho, da educação, da disciplina e da segurança, pois nenhum setor alcançará seu objetivo dentro de uma unidade penal sem que haja a colaboração, o compro- 
metimento, a responsabilidade e o entendimento de trabalho em equipe, respeitando suas necessidades e fragilidades. [...] Como agente penitenciário, uma de nossas inúmeras funçóes é garantir a ordem e a disciplina dentro do estabelecimento penal fazendo com que outros setores possam atuar como: social, educacional e médico, onde o conjunto desse trabalho irá influenciar diretamente a vida do apenado. (RODRIGUES, 2015, p. 88).

Sintetizando os objetivos do trabalho das diversas ciências e de seus profissionais no termo tratamento penal ${ }^{1}$ identifica-se, então, o paradigma que norteia o trabalho dentro da instituição total.

Paradigmas, no entender de Thomas Khun, são "as realizaçóes científicas universalmente reconhecidas que, durante algum tempo, fornecem problemas e soluçóes modelares para uma comunidade de praticantes de uma ciência” (1998, p. 13).

Com essas definiçóes preliminares, podemos conceber que dentro da instituição total denominada prisão atua uma constelação de profissionais, oriundos de diversas áreas de conhecimento, mas orientados por um mesmo paradigma "mesmo quando seus membros não o empregam da mesma maneira” diria Thomas Kuhn (1998, p. 221).

É dentro desse contexto que vamos analisar a relação entre ciências e suas implicações na educação e no trabalho dentro da prisão.

\section{RELAÇÃO ENTRE CIÊNCIAS E SABERES NO UNIVERSO PRISIONAL}

Não é fácil depreender uma relação hierárquica entre ciências como Direito, Medicina, Psiquiatria, Psicologia, Pedagogia, Serviço Social e Ciências Sociais, nem é o caso de aqui esmiuçar as distinçóes entre Ciências Jurídicas, Ciências Criminais e Criminologia tal qual fizeram Cesare Lombroso (1935 - 1909), Enrico Ferri (1856 - 1929), Roberto Lyra (1902 - 1982) e Nelson Hungria (1891 - 1969), ou as diferenças existentes entre as diversas nuances da Ciência Penitenciária, do 
Direito Penitenciário e da Penalogia. Porém, não há dúvidas quanto ao papel tutelar que exercem as Ciências Jurídicas sobre as demais ciências que atuam no ambiente penitenciário.

O estatuto epistemológico de cada ciência em particular é objeto da História da Ciência ${ }^{2}$, mas não obstante serem todos os saberes corresponsáveis pelos resultados últimos e não haver uma hierarquização de natureza científica, é desigual a atribuição de tarefas entre elas, reservando-se as funções normativas às ciências jurídicas, as executivas à administração penitenciária e as de recuperação, reeducação e ressocialização às ciências que se agasalham sob o amplo guarda-chuva da Criminologia, principalmente psicólogos, pedagogos, psiquiatras, cientistas sociais e assistentes sociais.

Aos profissionais dessas áreas reserva-se o papel de legitimar as normativas pelas quais o sistema subsiste, ignorando-se que tais profissionais, enquanto depositários de significativo repertório de conhecimentos científicos, poderiam e deveriam dar ao sistema a valiosa contribuição de que sua respectiva ciência é capaz.

A subordinação das ciências sociais, humanas, biológicas e da saúde à ciência jurídica é mais enfática ao constatarmos que seus profissionais não possuem nenhuma autonomia no trabalho penitenciário, pois têm sua atuaçáo rigidamente demarcada pela norma jurídica — notadamente o Código Penal Brasileiro, o Código de Processo Penal e a Lei de Execução Penal - e subordinam-se, também, aos ditames da segurança e da disciplina penitenciária, tornando-se, assim, meros executores de tarefas necessárias à instrução processual e à avaliação para concessão de benefícios ao sentenciado. Poder-se-ia afirmar que estão a serviço do sistema e não a serviço da pessoa humana momentaneamente privada da liberdade, sempre com funçôes subsidiárias ao diretor penitenciário, ao juiz, ao Ministério Público e ao Conselho Penitenciário ${ }^{3}$.

Os paradigmas que norteiam a Execução Penal, desde a prolatação da sentença de condenação até a reabilitação criminal ${ }^{4}$, e que conformam, portanto, o tratamento penal a ser dado ao preso, são todos oriundos das Ciências Jurídicas e, mais especificamente, do Direito Penal. Isso quer dizer que as ciências afins (MAZZUOLI, 2011), incluindo Psiquiatria, Pedagogia, Psicologia, Serviço Social, Ciências Sociais, Sociologia e outras, constituem meros apêndices das Ciências Jurídicas sendo sempre chamadas a explicar e 
a interpretar a criminalidade, a violência, o crime e o comportamento criminoso, mas não a intervir neles quando fora dos paradigmas traçados pelas ciências normativas. Essa relaçáo subalterna relega essas ciências aos campos da teorização acadêmica, da pesquisa empírica e da crítica social, mitigando, senão impossibilitando, sua intervenção tanto na formulação da política criminal e penitenciária quanto na condução do tratamento penal.

Camargo (1992, p. 74) afirma que

a subordinação profissional implica em perda de autonomia quase total dentro do sistema penitenciário. Mesmo levando em conta ser a autonomia profissional sempre relativa, nas prisóes essa relativização atinge o ponto máximo.

A responsabilidade por dar uma unidade teórica e conceitual ao chamado tratamento penal é tanto de cada ciência em particular quanto da comunidade científica conformada por seus profissionais e, principalmente, do Estado - gestor da política criminal e penitenciária e dos principais centros de formação e de pesquisa.

$\mathrm{Na}$ ausência de um posicionamento crítico das áreas de conhecimento e de seus profissionais, o Estado prefere manter sob tutela as ciências humanas, sociais e biológicas, servindo-se de seus conhecimentos apenas naquilo que se coaduna com seus propósitos político-ideológicos. As ciências jurídicas absorveram os demais campos de conhecimento e os tornaram estéreis, incapazes de dar contribuições significativas na discussão e resolução da problemática social e criminológica.

Entrevistas realizadas em sede de doutoramento por Roberto da Silva (2001), com profissionais das penitenciárias de Franco da Rocha, Feminina do Butantã, Centro de Ressocialização de Bragança Paulista e, mais recentemente, por Vanessa Rodrigues (2015), na Penitenciária Industrial de Guarapuava, mostram que nenhuma das ciências, isolada ou conjuntamente, possui ou adota uma reflexão teórica suficientemente consistente para imprimir uma linha de ação aos seus profissionais e que técnicos, gestores e agentes penitenciários possuem perspectivas diferentes sobre o mesmo trabalho. 
Bom, na verdade, pensando em termos ideais, é claro que deveria ter um conduta até mesmo para confecção do laudo, uma teoria específica que desse luz para o trabalho do psicólogo, mas isso não existe, fica a cargo de cada feudo que é a penitenciária. Para mim cada penitenciária é um feudo, é claro que eu sigo os preceitos da psicanálise que é com o que eu mais me identifico. (Psicólogo do Presídio de Franco da Rocha, 1998 apud SILVA, 2001, p. 131).

Nós, as Assistentes Sociais, não seguimos nenhuma linha teórica não. A gente vem, atende e faz por onde estar resolvendo os problemas. (Assistente Social do Presídio de Franco da Rocha, 1998 apud SILVA, 2001, p. 131).

Basicamente não adotamos nenhuma teoria criminológica. Valem mais as teorias psicológicas aprendidas durante a faculdade e o período de especialização, voltadas mais para as questóes humanas da presa, sem, entretanto, se apegar muito a isso. A uma criminosa que cometeu um homicídio ou um assalto, alguns testes são aplicados e aí sim, buscamos um embasamento teórico em livros e apostilas, mas eu particularmente me baseio mais nas entrevistas e no contato com elas. (Psicóloga da Penitenciária Feminina do Butantã, 1998 apud SILVA, 2001, p. 131).

O gestor penitenciário, diante do questionamento de Rodrigues (2015, p. 102) sobre a influência de sua ação no projeto de vida dos presos, afirma que "o planejamento das açóes que, de alguma forma, possam auxiliar no tratamento penal, passa pelo gestor da unidade, o qual ainda pode contribuir com uma postura ética e profissional, servindo como espelho aos presos”. Declarou, ainda, que na Penitenciária Industrial de Guarapuava, a reinserção social é o termo mais adequado ao atendimento da unidade prisional, ressaltando que "o objetivo é transformar pessoas capacitando-as para que sejam socializadas e reinseridas na sociedade”.

Se entendermos que as açóes do Estado na aplicação, execução e fiscalização da pena de privação de liberdade consistem, basicamente, no controle corporal do preso, monitorando o único bem constitucional que o ordenamento jurídico brasileiro coloca sub judice - a liberdade de ir e 
vir - a medida de sua eficácia na administração da pena poderia ser dada apenas pela taxa de fugas. Sob a perspectiva retributiva da pena, portanto, apenas muralhas e guardas seriam suficientes para alcançar esse propósito e evitar que o condenado frustre os objetivos estipulados na sentença.

Quando, entretanto, especialmente nas sociedades democráticas, entende-se a prisão sob uma perspectiva humanitária, a pena de privação da liberdade implica em conceber um processo de transformaçáo qualitativa do preso em uma perspectiva náo apenas retributiva ou repressiva, mas também preventiva da pena. Sob essa perspectiva, incluem-se as açóes de trabalho e educação nas prisóes e assume relevância o papel desempenhado pelas ciências tributárias das ciências jurídicas, cujos profissionais são chamados a prestar seu concurso na operação do sistema penitenciário.

Vera Malaguti Batista, no texto O proclamado e o escondido: a violência da neutralidade técnica, concluiu que laudos e estudos efetuados pela Psiquiatria, Psicologia e Serviço Social são recorrentemente utilizados por promotores e juízes para fundamentarem suas decisóes e se eximirem da responsabilidade de manter preso ou colocar em liberdade alguém de forma indevida, sem que nunca tenham ficado frente a frente com o sentenciado, conheçam as circunstâncias que o levou ao crime ou as condiçóes em que ele ou sua família vivem (BATISTA, 1997).

Se, como vimos, os paradigmas que orientam a Execução Penal são fornecidos pelas ciências jurídicas, há que se considerar que as demais áreas de conhecimento reúnem um corolário de saberes oriundo das ciências às quais se atribui as funçóes mais humanizadoras dentro do sistema penitenciário, como a Educação, a Psicologia e o Serviço Social, e o importante papel que exercem o trabalho, as artes, a cultura e o esporte.

Identifica-se, assim, a fragmentação epistemológica do conhecimento, à qual corresponde a fragmentaçáo das especialidades profissionais, bem como a fragmentação das políticas, programas, projetos e açóes destinadas ao tratamento dado às pessoas presas, sem que nenhuma área em particular alcance o seu desiderato, qual seja, restituir para a sociedade uma pessoa socialmente educada, respeitadora dos direitos dos outros e cumpridora dos seus deveres.

Roberto da Silva e Fábio Moreira já demonstraram, no artigo Objetivos educacionais e objetivos da reabilitaçâa penal: o diálogo possivel, que: 
Enquanto prevalecer a concepção de prisão como espaço de confinamento, de castigo, de humilhação e de estigmatização social a Educaçẫo não terá lugar na terapia penal, limitando-se a ser, como efetivamente é, apenas mais um recurso a serviço da administração penitenciária para ocupar o tempo ocioso de alguns poucos presos e evitar que se envolvam em confusões. (SILVA; MOREIRA, 2006, p. 13)

Tendo o Brasil o quarto maior sistema penitenciário do mundo, segundo dados do Departamento Penitenciário Nacional do Ministério da Justiça (BRASIL, 2014, p. 11), com mais de 600 mil pessoas em situação de privação de liberdade, com cerca de $63 \%$ deles com idade entre 18 e 35 anos, maioria de afrodescendentes, 70\% com o Ensino Fundamental incompleto, baixa qualificação profissional e menos de $15 \%$ envolvidos em atividades educacionais, como podem essas ciências, com os seus saberes e os seus profissionais, enfrentar o desafio do encarceramento em massa da juventude, as elevadas taxas de reincidência e a deterioração da dignidade humana nas prisóes brasileiras?

\section{ARTICULAÇÃO ENTRE CIÊNCIAS, EDUCAÇÃO E TRABALHO NA PRISÃO}

O ordenamento jurídico brasileiro impóe a obrigatoriedade do trabalho para o preso e que a oferta da educação, um dever do Estado e direito do cidadão, seja "promovida e incentivada com a colaboração da sociedade, visando ao pleno desenvolvimento da pessoa, seu preparo para o exercício da cidadania e sua qualificação para o trabalho", conforme art. 205 da Constituição Federal de 1988 (BRASIL, 1988).

A Resolução no 03, de 11 de março de 2009, do Conselho Nacional de Política Criminal e Penitenciária (CNPCP), em seu artigo $2^{\circ}$, ordena que

As açóes de educação no contexto prisional devem estar calcadas na legislaçáo educacional vigente no país e na Lei de Execução Penal, devendo atender as especifi- 
cidades dos diferentes níveis e modalidades de educação e ensino" (CNPCP, 2009).

A Resolução no 2, de 19 de maio de 2010, da Câmara de Educação Básica do Conselho Nacional de Educação (CNE/CEB), por sua vez, recomenda, em seu artigo $3^{\circ}$, inciso III, que a educação em prisóes

estará associada às açóes complementares de cultura, esporte, inclusão digital, educação profissional, fomento à leitura e a programas de implantação, recuperação e manutenção de bibliotecas destinadas ao atendimento à populaçáo privada de liberdade, inclusive as açóes de valorização dos profissionais que trabalham nesses espaços" (CNE, 2010).

O artigo 10, dessa mesma resolução, determina que:

As atividades laborais e artístico culturais deverão ser reconhecidas e valorizadas como elementos formativos integrados à oferta de educaçáo, podendo ser contempladas no projeto político-pedagógico como atividades curriculares, desde que devidamente fundamentadas. (CNE, 2010).

E, finalmente, o Decreto no 7.626, de 24 de novembro de 2011, no seu artigo $3^{\circ}$, inciso II, estabelece como diretriz principal do Plano Estratégico de Educaçáo no âmbito do sistema prisional a "integração dos órgãos responsáveis pelo ensino público com os órgãos responsáveis pela execução penal” (BRASIL, 2011a).

O que se depreende da breve análise dessas normas legais é que a educação em prisões deve resultar em uma perfeita integração entre a Lei de Execução Penal e a Lei de Diretrizes e Bases da Educação Nacional, entre a educação escolar e a educação náo escolar, gerando sinergias e convergências em relação aos princípios básicos que as fundamentam.

Ressignificar as assistências previstas nos artigos 10 e 11 da LEP, por exemplo, possibilitaria às áreas de conhecimento e respectivos profissionais ressignificarem, também, suas práticas, explorando o poten- 
cial pedagógico implícito em cada uma delas, com ganhos significativos para o trabalho profissional, para a Educação e para a melhoria das condiçóes de cumprimento da pena.

Nesse sentido, a assistência material, que consiste em prover o preso dos gêneros básicos para a vida em confinamento, possui a gênese de uma Educação Patrimonial, Educação para o Consumo Responsável e, até mesmo, Educação Financeira e Ambiental, com foco na sustentabilidade e futuras geraçóes.

Médicos e enfermeiros, em vez de se ocuparem apenas de emergências e de tratamento das doenças típicas da prisão, como tuberculose, sarna e doenças sexualmente transmissíveis, poderiam realizar práticas de Educação em Saúde, uma vez que a legislação permite que eles capacitem presos como agentes promotores de saúde.

Bacharéis em Direito e profissionais da área jurídica, por sua vez, ajudariam a renovar o próprio ensino da matéria e as relações que permeiam a área se aprendessem e realizassem Educação em Direitos e não apenas a defesa técnica em processos judiciais.

Assistentes sociais renovariam suas práticas se trabalhassem, nas prisóes, a Educação para a Cidadania, com ênfase na habilitação da pessoa em situação de privação de liberdade para o exercício de direitos civis, sociais e políticos, com foco na promoção da cidadania e das políticas públicas.

A Psicologia, de outra parte, tem toda vocação para trabalhar as diversas dimensões da identidade, da subjetividade, das relações humanas e sociais e, juntamente com a Psiquiatria, poderia se ocupar mais detidamente da saúde mental das pessoas em situação de privação de liberdade do que da confecção de laudos e pareceres para progressão de pena ou concessão de benefícios ao longo da execução penal.

A Educação Escolar tem seus próprios desafios, pois constitui a base para o exercício de direitos civis, sociais e políticos. Desse modo, é seu papel promover a alfabetização e a elevação da escolaridade, com certificação e associada à qualificação para o trabalho, para aqueles que náo concluíram a Educação Básica - Ensino Fundamental e Ensino Médio. Ademais, colocam-se as possibilidades de oferta da Educação Técnica e Profissional, Ensino a Distância e acesso à Educação Superior. 
Ressalte-se que, com essas áreas de conhecimento, não se pode repetir o que ocorreu com a categoria Trabalho, que, historicamente, não cumpriu os objetivos de ser educativo e produtivo, e tampouco os propósitos para os quais foi instituído na prisão como obrigatório, ou seja, indenização dos danos causados pelo crime, assistência à família, custeio das despesas pessoais e ressarcimento das despesas do Estado com sua manutenção na prisão. Fundamentalmente, usou-se e abusou-se do trabalho para remição da pena, mas ele não demonstrou fomentar no preso os valores próprios da cultura do trabalho, não resultou em qualificação profissional, não possibilitou a atualização em relação os modos de produção vigentes na sociedade e não garantiu sua empregabilidade após a prisão.

Emoldurando a abordagem pedagógica que as áreas de conhecimento podem imprimir às suas práticas, de forma transversal a todas elas, faz-se necessário considerar, ainda, o lugar a ser ocupado pela cultura, pelas artes e pelo esporte.

A lógica que preside a articulação entre a educação escolar e não escolar nas prisóes é de valorizar toda e qualquer iniciativa positiva por parte do preso, e isso requer que cada atividade a ser desenvolvida cumpra alguns pré-requisitos quanto à sua oferta e organizaçáo, quais sejam, ter objetivos e metas definidos, cumprir um programa regular, com periodicidade e carga horária definidas, ser ministrada por profissionais qualificados, ser passível de avaliação que possa, ao final, resultar em certificação.

Coloca-se, assim, a importância da certificação, pois atestaria não apenas a trajetória da pessoa em situação de privação de liberdade por um processo educativo, mas legitimaria o usufruto da remição da pena, com base na Lei no 12.433, de 29 de junho de 2011 (BRASIL, 2011b) e na Recomendação no 44, de 26 de novembro de 2013, do Conselho Nacional de Justiça (CNJ, 2013), por ter alcançado com êxitos os objetivos e metas da educação e do tratamento penal.

Nesse sentido, sistematizamos a Figura 1, visando ilustrar a possibilidade de atuação conjunta das áreas do conhecimento presentes no sistema prisional, em torno de práticas educacionais, tanto para suprir o sistema penitenciário do projeto político pedagógico indicado na Resolução CNE/CEB no 2/2010 (CNE, 2010), quanto alcançar as necessárias articulaçóes e integração entre as diversas áreas de conhecimento e seus profissionais. 


\section{Figura 1}

Projeto político pedagógico para a educação em prisóes

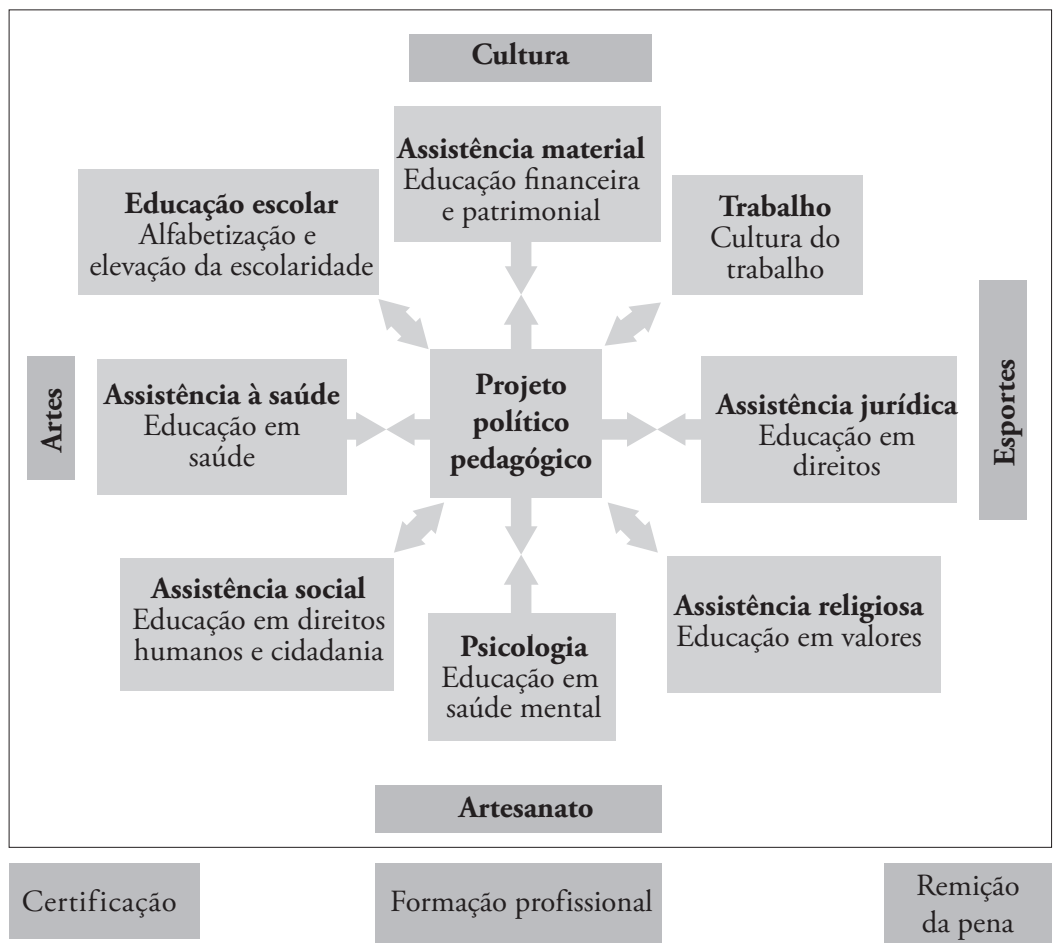

Fonte: Silva (2015).

\section{REFERÊNCIAS}

BATISTA, V.M. O Proclamado e o Escondido: a violência da neutralidade técnica. In: . Discursos Sediciosos. n 3. Rio de Janeiro: Instituto Carioca de Criminologia, 1997. p. 77-83.

BRASIL. Decreto-lei n. 2848, de 7 de dezembro de 1940. Código Penal. Diário Oficial da União, Brasília, DF, p. 23911, 31 dez. 1940. Seção 1.

. Decreto-lei n. 3689, de 3 de outubro de 1941. Código de Processo Penal. Diário Oficial da União, Brasília, DF, p. 19699, 13 out. 1941. Seção 1. 
. Lei n. 7210, de 11 de julho de 1984. Institui a Lei de Execução Penal. Diário Oficial da União, Brasília, DF, p. 10227, 13 jul. 1984. Seção 1.

. Constituição (1988). Constituição da República Federativa do Brasil. Brasília, DF: Senado Federal, 1988.

. Lei n. 9394, de 20 de dezembro de 1996. Estabelece as diretrizes e bases da educação nacional. Diário Oficial da Uniāo, Brasília, DF, p. 27833, 23 dez. 1996. Seção 1.

. Lei n. 12.433, de 29 de junho de 2011. Altera a Lei no 7.210, de 11 de julho de 1984 (Lei de Execução Penal), para dispor sobre a remiçáo de parte do tempo de execução da pena por estudo ou por trabalho. Diário Oficial da União, Brasília, DF, p. 1, 30 jun. 2011b. Seção 1.

. Presidência da República, Casa Civil. Decreto n. 7.626, de 24 de novembro de 2011. Institui o Plano Estratégico de Educaçáo no âmbito do Sistema Prisional. Diário Oficial da Uniâo, Brasília, DF, p. 2, 25 nov. 2011a. Seção II.

- Levantamento Nacional de Informaçóes Penitenciárias INFOPEN-Junho de 2014. Brasília: Departamento Penitenciário Nacional; 2014. Disponível em $<$ http://www.justica.gov.br/noticias/mj-divulgara-novo-relatorio-do-infopennesta-terca-feira/relatorio-depen-versao-web.pdf $>$. Acesso em 13 jan. 2016.

CAMARGO, M.S. Assistentes sociais no sistema penitenciário paulista: a crença na reabilitação. 1992. 187f. Tese (doutorado). Pontifícia Universidade Católica de São Paulo, São Paulo.

CONSELHO NACIONAL DE EDUCAÇÃO (CNE). Resolução no 2, de 19 de maio de 2010. Dispóe sobre as Diretrizes Nacionais para a oferta de educação para jovens e adultos em situação de privação de liberdade nos estabelecimentos penais. Diário Oficial da União, Brasília, DF, p. 20, 20 maio 2010. Seção 1.

CONSELHO NACIONAL DE JUSTIÇA (CNJ). Recomendação no 44, de 26 de novembro de 2013. Dispóe sobre atividades educacionais complementares para fins de remição da pena pelo estudo e estabelece critérios para a admissão pela leitura. Brasília, DF, DJE/CNJ n 224, p. 2, 27 nov. 2013.

CONSELHO NACIONAL DE POLÍTICA CRIMINALE PENITENCIÁRIA (CNPCP). Resolução no 03, de 11 de março de 2009. Dispóe sobre as Diretrizes Nacionais para a Oferta de Educação nos estabelecimentos penais. Diário Oficial da União, Brasília, DF, p. 22-23, 25 mar. 2009. Seção 1.

GOFFMAN, E. Manicômios, prisóes e conventos. São Paulo: Perspectiva, 1986.

KUHN, T. A Estrutura das revoluçóes cientificas. São Paulo: Perpsectiva, 1998. 
MAZZUOLI, V. O. Direito e ciências afins -Tribunal Penal Internacional e o Direito Brasileiro. 3. ed. São Paulo: Revista dos Tribunais, v. 3, 2011.

RODRIGUES, V.E.R. A relação da educação e do trabalho na Penitenciária Industrial de Guarapuava: mudanças e permanências históricas. 2015. $130 \mathrm{f}$. Dissertação (mestrado). Universidade Estadual do Centro-Oeste, Guarapuava.

SILVA, R. A eficácia sócio-pedagógica da pena de privação da liberdade. 2001. Tese (doutorado). Faculdade de Educação. Universidade de São Paulo, São Paulo.

2015.

. O projeto político pedagógico para educação em prisóes. Cidade: Editora,

SILVA, R.; MOREIRA, F.A. Objetivos educacionais e objetivos da reabilitação penal: o diálogo possível. Revista Sociologia Jurídica, São Paulo, n. 3, 2006.

\section{NOTAS}

1. Definição de tratamento penal referenciada em PIMPÃO FERREIRA, M. R. N.; VIRMOND, S. M. (Orgs). Práticas de tratamento penal nas unidades penais do Paraná. Curitiba: Secretaria de Estado da Justiça e Cidadania, 2011.

2. Para aprofundar o tema veja RONAN, C. A. História ilustrada da ciência. Jorge Zahar (trad.). Rio de Janeiro: Jorge Zahar Editor, 1987.

3. Para entender um pouco como essas ciências subsidiárias provocaram mudanças no pensamento jurídico-penal brasileiro, ver ANDRADE, V.R.P. Do paradigma etiológico ao paradigma da reação social: mudança e permanência de paradigmas criminológicos na ciência e no senso comum. Seqüência: Estudos Jurídicos e Políticos, Florianópolis, v. 30, p. 24-36, jan. 1995.

4. Conforme nos artigos 93 a 95 do Código Penal, e 743 a 750 do Código de Processo Penal.

Recebido em 11 de setembro de 2015.

Aceito em 22 de fevereiro de 2016. 